\title{
Synthesis And Study The Concentration Effect On The Photocatalytic Activity of Titania Nanoparticles As Anti-Bactria Using Reactive Magnetron Sputtering Technique
}

Firas J. Al-Maliki ( $\square$ dr.firas1990@yahoo.com ) University of Baghdad

Maryam A. Al-Rubaiy

University of Baghdad

\section{Research Article}

Keywords: TiO2, Photocatalysis, antibacterial, single and mixed phase, DC Reactive Magnetron Sputtering Technique

Posted Date: September 14th, 2021

DOl: https://doi.org/10.21203/rs.3.rs-793714/v1

License: (9) (i) This work is licensed under a Creative Commons Attribution 4.0 International License. Read Full License 


\section{Abstract}

In this work, the dc reactive magnetron sputtering technique was used to prepare and deposit nanostructured titanium dioxide $\left(\mathrm{TiO}_{2}\right)$ thin films on glass substrates. Titanium dioxide thin films of mixed phase (anatase + rutile) and single phase (anatase) were prepared using different gas mixing ratios, and for both of the two phases, they were diagnosed via x-ray diffraction (XRD). It was found that the contents of rutile in mixed phase dependent on the deposition time increased from the ratio of $40 \%$ to $46 \%$ and $50 \%$ as the deposition time increased from 3 hours to 3.30 and 4 hours. The photocatalytic activity of the mixed and single phase $\mathrm{TiO}_{2}$ was measured by kill the bacteria Escherichia coli (E.Coli) under exposure to UV-radiation. It was proven that the photocatalytic activity in the mixed phase $\left(\mathrm{TiO}_{2}\right)$ gave better results weight fraction is $40 \%$ as an antibacterial activity. Based on the obtained results antibacterial activity of dioxide titanium nanoparticles was dependent on the concentration and phase of $\mathrm{TiO}_{2}$ and weight fraction of mixed-phase.

\section{Introduction}

The research interest in nanostructured titanium dioxide $\left(\mathrm{TiO}_{2}\right)$ thin films is rapidly rising due to its numerous and potential applications, such as photocatalysis, photonics, optoelectronics, electrochemistry, and photoelectrochemistry [1]. These applications are used for the optical, electrical, chemical, and mechanical characteristics of $\mathrm{TiO}_{2}$ thin films and nanoparticles [2]. Because of its outstanding properties, such as nontoxicity, high photocatalytic activity, chemical stability, ability to be coated as a thin film on a substrate, and Friendly to the environment, $\mathrm{TiO}_{2}$ is being hailed as a potential photocatalyst among all semiconductor photocatalysts. [3]. the average nanocrystalline size, crystallinity, specific surface area, and phases involved are all known to affect the photocatalytic activity of pure- $\mathrm{TiO}_{2}$ $[4,5]$. $\mathrm{TiO}_{2}$ exists as three different polymorphs: anatase, rutile, and brookite. The main source and the most stable form of $\mathrm{TiO}_{2}$ is rutile, In terms of photocatalytic activity, anatase $\mathrm{TiO}_{2}$ is more active than rutile $\mathrm{TiO}_{2}$. [6].

The mixed $\mathrm{TiO}_{2}$ phase anatase/rutile, which is more popular than the single anatase or rutile phase, has greater photocatalytic activity than the single anatase or rutile phase, which is attributed to a synergistic effect between the two phases. [7]. The co-presence of anatase and rutile crystallites induces a high level of photocatalytic activity; the transfer of photoexcited electrons and positive holes between interconnecting anatase and rutile particles may enhance charge separation and hence improve the efficiency of utilization of electron-hole pairs [8]. Additional characterizations confirmed electron transport between the two phases, suggesting that phase composition is a fundamentally important factor in high photocatalytic activity [9].

The function of the Titania photocatalyst can be divided into these major categories: Purifying water, Preventing contamination, Deodorizing, Purifying the air self-cleaning, and Anti-bacteria [10]. Titania nanoparticles have a broad spectrum of activity against microorganisms, including Gram-negative and 
positive bacteria, as well as fungus, which is especially important for drug-resistant strains. Furthermore, prior research has shown that $\mathrm{TiO}_{2}$ may not only kill a complex cellular congregation with major implications in pathogenicity (fungal) as concentration increases, but it can also prevent fungus development at lower concentrations [11-13].

Synthesizing $\mathrm{TiO}_{2}$ can be done in a variety of ways. $\mathrm{TiO}_{2}$ films may be made using a variety of physical vapor deposition (PVD) and chemical vapor deposition (CVD) processes and techniques, including solgel, pulsed-laser deposition, ion beam, and dc magnetron sputtering [14-16]. The dc closed-field unbalanced reactive magnetron sputtering technique offers several advantages over other techniques, particularly when it comes to producing very pure and homogenous thin films on vast areas of substrates at low processing temperatures. Changes in operating parameters such as total gas pressure, working gas pressures, inter-electrode distance, gas mixing ratio, electrical discharge power, substrate temperature, cooling rate, and sputtering time can alter the characteristics of sputtered $\mathrm{TiO}_{2}$ films [1719].

In the present work, the anti-bacterial effect of $\mathrm{TiO}_{2}$ nanoparticles was investigated as a function of concentration under light irradiation.

\section{Experimental Part}

In the present work, Titanium Dioxide nanostructures were synthesized as thin films using reactive magnetron plasma sputtering deposition method. To produce $\mathrm{TiO}_{2}$ thin coatings on glass substrates, the electric power for glow discharge which in turn generating plasma in the system was provided by a dc power supply, connected to the electrodes. The highest electrical power was $150 \mathrm{~W}$, with a discharge voltage of $3 \mathrm{kV}$ with a discharge current of $50 \mathrm{~mA}$, and a selected distance of $4 \mathrm{~cm}$ between the target and the substrate. More information about the system's working conditions and parameters tuning may be obtained elsewhere [20-21].

The sputtered target was a titanium sheet with a purity of $99.99 \%$. A two-stage rotary pump (Edward 8 $\mathrm{m}^{3} / \mathrm{h}$ ) was run at a base pressure of around $3 \times 10^{-2} \mathrm{mbar}$ to prevent contamination of the chamber during the deposition process .To produce the discharge plasma, a glass substrate was exposed to pure argon gas at the start of the thin-film preparation process. All samples were reactively sputtered in a combination of Argon gas (99.99\%) as precursor gas and Oxygen gas (99.99\%) as reactive gas. The film samples were prepared as a function of different deposition time $(3,3.30$, and 4 hours) and three different mixing ratios of $\mathrm{Ar}_{2} \mathrm{O}_{2}$ gases (50:50, 67:33, and 80:20). Before pumping the gas mixture to the deposition chamber, a stainless steel mixer was employed to control the mixing ratios. Conjunctional freezing-assisted ultrasonic extraction was used to extract nanopowder from thin-film samples [22]. Figure (1) shows a photo of $\mathrm{TiO}_{2}$ sample, synthesized in the present work, as thin film and as extracted powder. 
The bacteria Escherichia coli (E. coli) samples have been selected and prepared for testing in the application of photocatalytic activity. For 24 hours, Escherichia coli have been cultured in nutrient broth at $37^{\circ} \mathrm{C}$. Before overnight growth, a small swab of the E. coli sample by using a sterile swab has been taken and distributed evenly on the surface of nutrient agar. $\mathrm{TiO}_{2}$ nanopowder (extracted from the prepared films) of different concentrations $0.25,0.5$, and $1 \mathrm{~g}$ have been dissolved in sterilized deionized water by using an ultrasonic bath, homogenized by a vortex mixer, added to the plates, and then the dishes have been exposed to UV irradiation (200-400 nm) for 90 minutes. The UV source is placed at a distance of 10 $\mathrm{cm}$ from the Petri dish. Finally, incubated at $37^{\circ} \mathrm{C}$ for 24 hour and then the formation of growth inhibitory zones have been examined, as shown in the figure (2).

\section{Results And Discussion}

The crystalline structure of the samples synthesized under various processing parameters was investigated using $X$-ray Shimadzu diffractometer with Cu Ka radiation $(\lambda=1.54060 \AA)$ at $40.0 \mathrm{kV}$ and 30 $m A$, Figure (3) include $x$-ray diffraction patterns. The first one (A) represents the mixing phase structure (anatase /rutile) of one of the prepared $\mathrm{TiO}_{2}$ samples, in which the diffraction peaks at $25.2^{\circ}, 37.8^{\circ}, 48^{\circ}$, $55.1^{\circ}, 56.7^{\circ}, 62.8^{\circ}, 69.2^{\circ}, 69.8^{\circ}$, and $75.4^{\circ}$ are corresponding to (101), (004), (200), (105), (211), (118), (116), (220) and (125) crystal planes. According to JCPDS, card no. 21-1272, they confirm the formation of the anatase $(\mathrm{A})$ phase. While the peaks at $\left(27.5^{\circ}, 36^{\circ}, 41.3^{\circ}, 44.1^{\circ}, 54.5^{\circ}\right.$ and $\left.64.3^{\circ}\right)$ Correspond to the rutile phase (110), (101), (111), (210), (211) and (310) crystal planes according to the JCPDS card no. 00021-1276 [23].The second pattern (B) indicates the single phase structure (anatase only) of the samples which are prepared with making a heat sink under the substrate. The weight fraction $(f)$ of the rutile phase in an anatase-rutile combination may be calculated using the equation [7]:

$$
f=\frac{1}{1+0.88 \frac{I A}{I R}}
$$

Here $f$ is the weight fraction of rutile in mixed-phase (anatase + rutile) and $I_{A} / I_{R}$ is the ratio of the intensity of anatase $\left(I_{A}\right)$ phase to that of rutile $\left(I_{R}\right)$ phase that is determined from the x-ray intensities. For samples prepared following deposition times of $3,3: 30$, and 4 hours, the relative quantities of rutile in mixed-phase (anatase-rutile) samples were $40 \%, 46 \%$, and $50 \%$, respectively.

On the other side, the crystallite size of the particles was calculated from Deby-Scherrer's equation using the XRD line broadening [21].

$$
D=\frac{K \lambda}{\beta \cos \theta}
$$

Here $D$ is the crystallite size, $\theta$ is the diffraction angle, $\lambda$ is the $x$-ray radiation wavelength $(0.15406 \mathrm{~nm})$ for CuK, $\mathrm{K}$ is a constant typically chosen as 0.89 , and $\beta$ is the full-width at half-maximum (FWHM) [24]. At 
gas mixing ratios of $A r: O_{2}$ equal to $0: 50,67: 33$, and $80: 20$, the average crystallite size determined to be $18.3,19.9$, and $17.5 \mathrm{~nm}$ respectively for mixing phases (anatase + rutile).

In order to infer the structural properties of forming $\mathrm{TiO}_{2}$ via sputtering method, Fourier-transform infrared (FTIR) spectroscopy in the range of $400-4000 \mathrm{~cm}-1$ (using Shimadzu 8400 S FTIR) has been employed as shown in the figure (4). The IR absorption bands appeared at around 3454, $1637 \mathrm{~cm}-1$ corresponds to the symmetric/asymmetric stretching and bending modes of vibration of a hydroxyl group ( $\mathrm{O}-\mathrm{H}$ bond) present in the structure, which indicate the presence of traces of water molecules due to humidity [25-26]. The peak at $420 \mathrm{~cm}-1$ is attributed to $\mathrm{Ti}-\mathrm{O}-\mathrm{Ti}$ bonds in the $\mathrm{TiO}_{2}$ network, whereas the band assigned to Ti-O stretching vibration is at 444 and $653 \mathrm{~cm}-1$. As a result, the prepared samples, via sputtering method, may be described as extremely pure in which no peaks reflect the existence of any impurities.

AFM (Atomic force microscopy) was used to study the surface morphology. Figure (5) shows twodimensional and three-dimensional AFM images of a $\mathrm{TiO}_{2}$ sample prepared with an Ar: $\mathrm{O}_{2}$ mixing ratio of 50:50 and a $3 \mathrm{~h}$ deposition time with an average roughness of $3.47 \mathrm{~nm}$ and a root mean square $\left(R_{\text {r.m.s. }}\right)$ value of $4.33 \mathrm{~nm}$, a significantly homogeneous distribution of $\mathrm{TiO}_{2}$ nanoparticles was generated. The large surface area to volume ratio of produced $\mathrm{TiO}_{2}$ nanoparticles may provide an advantage for using such surfaces in photonic and optoelectronic devices that use $\mathrm{TiO}_{2}$ nanostructures. Photocatalysts are another major application of $\mathrm{TiO}_{2}$ nanostructures with a high surface area to volume ratio.

The UV-visible spectroscopy was studied in the spectral region of $300-800 \mathrm{~nm}$ by recording the absorption spectra of mixed-phase nanocrystalline $\mathrm{TiO}_{2}$ film samples containing various quantities of rutile as illustrates in figure (6). For a sample with a $40 \mathrm{wt} . \%$ rutile phase, an absorption edge was found at around $339 \mathrm{~nm}$, whereas this edge was shifted to approximately 351 and $437 \mathrm{~nm}$ for samples with 46 and $50 \mathrm{wt} . \%$ rutile phase, respectively.

The optical energy band gap $\left(E_{g}\right)$ of nanocrystalline $\mathrm{TiO}_{2}$ films can be calculated from their absorption spectra using the following equation [27-28]:

$$
(\alpha h v)^{\mathrm{r}}=\mathrm{A}\left(h v-\mathrm{E}_{\mathrm{g}}\right)
$$

where $\mathrm{h}$ is Planck's constant, $v$ is the frequency of incident photon., $\mathrm{A}$ is constant, , $\mathrm{a}$ is the linear absorption coefficient, and $r$ is a fixed value that depends on the type of the optical transition. The value of $r$ is choose to be 0.5 indicates direct allowed transitions.

The band gap of mixed-phase nanocrystalline $\mathrm{TiO}_{2}$ with rutile $40 \mathrm{wt} . \%$ was estimated to be $3.43 \mathrm{eV}$, as shown in figure (7). While it becomes 3.39 and $3.35 \mathrm{eV}$, as the quantity of rutile is increased to 46 and 50 wt.\%, respectively. This decrease in energy band gap is ascribed to the charge-separation mechanism (CSM) [29] 
Figure (8) shows the absorption spectrum of single-phase (anatase) $\mathrm{TiO}_{2}$ nanostructures after 3 hours time deposition with a heat sink under the substrate using a 50:50 gas-mixing ratio. Figure (9) depicts the energy of this directly allowed band gap, which was determined to be $3.21 \mathrm{eV}$ in as-deposited Nanostructured $\mathrm{TiO}_{2}$ thin films with an $\mathrm{Ar}: \mathrm{O}_{2}$ mixing ratio50:50.

Figure (10) depicts the antibacterial effectiveness of $\mathrm{TiO}_{2}$ nanoparticles at different concentrations ( 0.25 , 0.5 , and 1$) \mathrm{g}$ for (single and mixed) phase against E. coli before and after photocatalytic treatment. The $\mathrm{TiO}_{2}$ nanoparticles' activity is associated with the light-induced generation of free radicals, which causes peroxidation when the radical reacts with the bacterial cell membrane. The extremely active oxygen species produced can oxidize organic compounds resulting in the disassembly and elimination of bacterial. The results showed that a concentration of $1 \mathrm{~g}$ of mixing phases of dioxide titanium nanoparticles has good antibacterial effects more than other concentrations. Based on the attained results anti-bacterial activity of dioxide titanium nanoparticles was depended on the concentration, phase of $\mathrm{TiO}_{2}$, and weight fraction of mixed-phase.

\section{Conclusion}

In this study, it was shown that the weight fraction of the rutile phase in the mixing phase structure rutile /anatase depends on the deposition time. On the same path, the synthesis of anatase $\mathrm{TiO}_{2}$ can be successfully achieved without any thermal treatment via this configuration of sputtering. On the other side, it was observed that the single phase and mixing phase of $\mathrm{TiO}_{2}$ have anti-bacterial activity with slightly preference for anatase phase. Also the anti-bacterial activity of mixing phase $\mathrm{TiO}_{2}$ change with the rutile content, where $40 \%$ rutile content shows more activity than other contents.

\section{Declarations}

Authors declare that they do not have any conflict of interest related to this work

\section{References}

[1] Jin, Y., Li, G., Zhang, Y., Zhang, Y., Zhang, L.: Photoluminescence of anatase $\mathrm{TiO}_{2}$ Thin films are achieved bythe addition of $\mathrm{ZnFe}_{2} \mathrm{O}_{4}$. J. Phys. Condens. Matter. 13, L913-L918 (2001)

[2] Karabay, I., Aydın Yüksel, S., Ongül, F., Öztürk, S., Asli, M.: Structural and optical characterization of TiO2thin films prepared by sol-gel process. Acta Phys. Pol. A 121(1), 265-267 (2012)

[3] Wang, Y.W., Huang, Y., Ho, W.K., Zhang, L.Z., Zou, Z.G., Lee, S.C.: Biomolecule controlled hydrothermal synthesis of $\mathrm{C}-\mathrm{N}$-S-tridoped TiO2 nanocrystalline photocatalysts for NO removal under simulated solar 
light irradiation. J. Hazard. Mater. 169, 77-87. 2009.

[4] Baiju, K.V., Shukla, S., Sandhya, K.S., James, photocatalytic activity of Sol-Gel-Derived nanocrystalline Titania, j.Phys.Chem. C, 111(21), 7612-7622, 2007.

[5] MehranRiazian, Electrical properties, and enhancement of photocatalytic activity of TiO2nanorods doped with SiO2, S. Afr.j.chem.(Online), vol.70, 2017.

[6] Fasciani, C., Lanterna, A.E., Giorgi, J.B., Scaiano, J.C., Visible light production of hydrogen by ablated graphene: water splitting or carbon gasification, J.Am.Chem.soc. 139, 11024-11029, 2017.

[7] Firas J. Al-Maliki1, Oday A. Hammadi, Esraa A. Al-Oubidy, Optimization of Rutile/Anatase Ratio in Titanium Dioxide Nanostructures prepared by DC Magnetron Sputtering Technique, Iraqi Journal of Science, Vol. 60, Special Issue, pp: 91-98, 2019.

[8] Hurum, D.C., Agrios, A.G., Gray, K.A., Rajh, T. and Thurnauer, C. "Explaining the Enhanced Photocatalytic Activity of Degussa P25 Mixed-Phase $\mathrm{TiO}_{2}$ Using EPR", J. Phys. Chem. B, 107: 4545. 2003.

[9] Hurum, D C., Gray, K A., Rajh, T. and Thurnauer, M C. "Recombination pathways in the Degussa P25 formulation of $\mathrm{TiO}_{2}$ : Surface versus lattice mechanisms", J PhysChem B, 109: 977-980.2005

[10] M. Kaneko and I. Okura, In Photocatalysis: Science and Technology (Kodansha, 2002), p. 157.

[11] F. Haghighi1, S. RoudbarMohammadi, P. Mohammadi, S. Hosseinkhani, R.Shidpour, Antifungal Activity of TiO2 nanoparticles and EDTA on Candida albicansBiofilms, Infection Epidemiology \& Medicine, Vol 1, No 1, Summer 2013.

[12] Berridge MV, Tan AS, Coy KDM, Wang R. TheBiochemical and Cellular Basis of Cell Proliferation Assays That Use Tetrazolium Salts.Biochemica; 4:14-19, 1996.

[13] Dunne WM. Bacterial adhesion: seen any goodbiofilms lately. ClinMicrobiol Rev; 15:155-166, 2002.

[14] M.H. Habibi, N. Talebian; The effect of annealing on photocatalytic properties of nanostructured titanium dioxide thin films, Dyes Pigments 73 (1) 103-110., 2007

[15] M. Stoller, M. Mescia, C. Valencia Peroni, A. Chianese; Production Of Nanoparticles Of Titanium Dioxide By Using A Spinning Disc Reactor, Chem. Eng. Trans. 11 (2007)71-76.

[16] R. Vijayalakshmi, V. Rajendran;Synthesis and characterization of nano-TiO2 via different methods,Arch. Appl. Sci. Res. 4 (2) (2012) 1183-1190.

[17] A.A. Hussain, H.S. Wahab; Synthesis and spectroscopic characterization of anatase $\mathrm{TiO}_{2}$ nanoparticles, Int. J. Nanotech. Nanosci. 2 (2014) 1-6. 
[18]Y. Yang, Q. Zhang, B. Zhang, W.B. Mi, L. Chen, L. Li, C. Zhao, E.M. Diallo,X.X. Zhang; The influence of metal interlayers on the structural and optical properties of nanocrystalline TiO2 films, Appl. Surf. Sci. 258 (10) (2012) 4532-4537.

[19] W.B. Mi, E.Y. Jiang, H.L. Bai; Structure, magnetic and optical properties of poly-crystalline Co-doped TiO2 films, J. Magn. Magn. Mater. 321 (16) (2009) 2472-2476.

[20] O.A. Hammadi, M.K. Khalaf, F.J. Kadhim and B.T. Chiad, Bulg; Operation Characteristics of a ClosedField Unbalanced Dual-Magnetrons Plasma Sputtering System. J. Phys., 41(1) (2014) 24-33.

[21] Firas J. Kadhim*, Esraa A. Al-Oubidy; Effect of Gas Mixing Ratio on Energy Band Gap of MixedPhase Titanium Dioxide Nanostructures Prepared by Reactive Magnetron Sputtering Technique.J.Phys., Vol. (14), No. (4), 2018, 19-23.

[22] O.A. Hammadi, "Production of Nanopowders from Physical Vapor Deposited Films on Nonmetallic Substrates by Conjunctional Freezing-Assisted Ultrasonic Extraction Method", Proc. IMechE, Part N, J. Nanomater. Nanoeng. Nanosys., 232(4), 135-140 (2018).

[23] A. Hu, X. Zhang, D. Luong, K. D. Oakes, M. R. Servos, R. Liang, S. Kurdi, P. Peng, Y. Zhou; Adsorption and Photocatalytic Degradation Kinetics of Pharmaceuticals by $\mathrm{TiO}_{2}$ Nanowires During Water Treatment, Waste Biomass Valoriz., 3 (2012) 443-449.

[24] K. Balachandran, R. Venckatesh and R. Sivaraj; Synthesis of nano TiO2-SiO2 composite using sol-gel method: Effect on size, surface morphology and thermal stability, Int. J. Eng. Sci. Technol., 2(8) (2010) 3695-3700.

[25] J. Wei, L. Zhao, S. Peng, J. Shi, Z. Liu, W. Wen, Wettability of urea-doped $\mathrm{TiO}_{2}$ nanoparticles and their high electrorheological effects, J. Sol-gel Sci. Technol. 47(2008) 311-315.

[26] A. Kathiravan, R. Renganathan, Photosensitization of colloidal $\mathrm{TiO}_{2}$ nanoparticles with phycocyanin pigment, J. Colloid Interface Sci. 335(2009) 196-202.

[27] A. Zachariah, K. V. Baiju, S. Shukla, K. S. Deepa, J. James, K. G. K. Warrier, "Synergistic Effect in Photocatalysis As Observed for Mixed-Phase Nanocrystalline Titania Processed via Sol-Gel Solvent Mixing and Calcination" J. Phys. Chem. C, Vol. 112, pp. 11345-11356, 2008.

[28] Zhao Y, Li C, Liu X, Gu F, Jiang H, Shao W, Zhang L, He Y, "Synthesis and optical properties of $\mathrm{TiO}_{2}$ nanoparticles", Mater Lett, Vol. 61, pp. 79-83, 2007.

[29] A. Zachariah, K.V. Baiju, S. Shukla, K.S. Deepa, J. James and K.G.K. Warrier, "Synergistic Effect in Photocatalysis As Observed for Mixed-Phase Nanocrystalline Titania Processed via Sol-Gel Solvent Mixing and Calcination", J. Phys. Chem., Vol. C 112, pp. 11345-11356, 2008. 


\section{Figures}

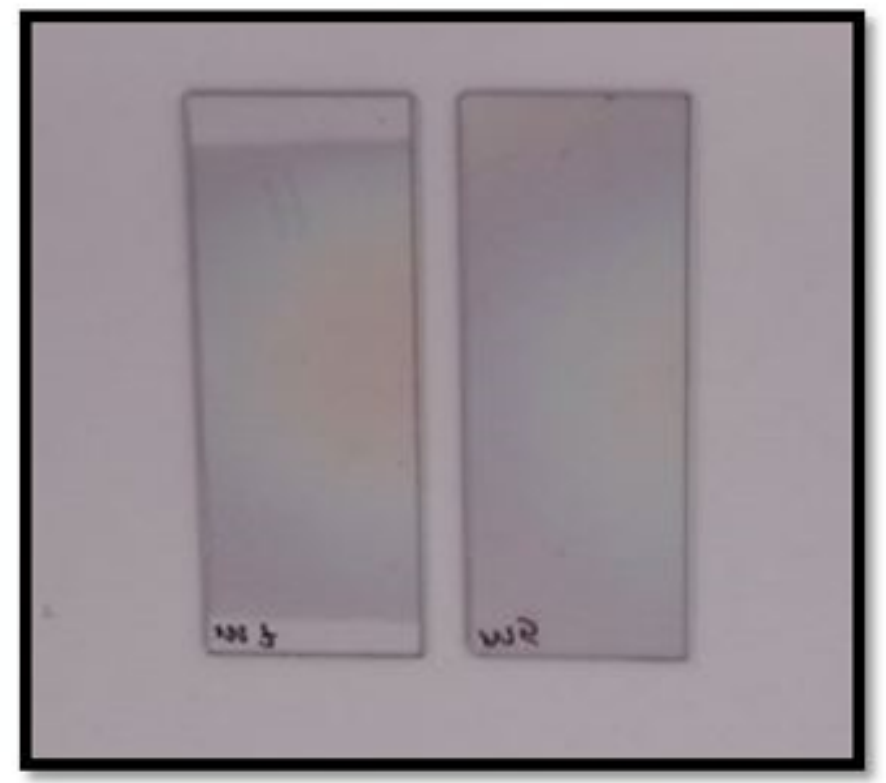

(A)

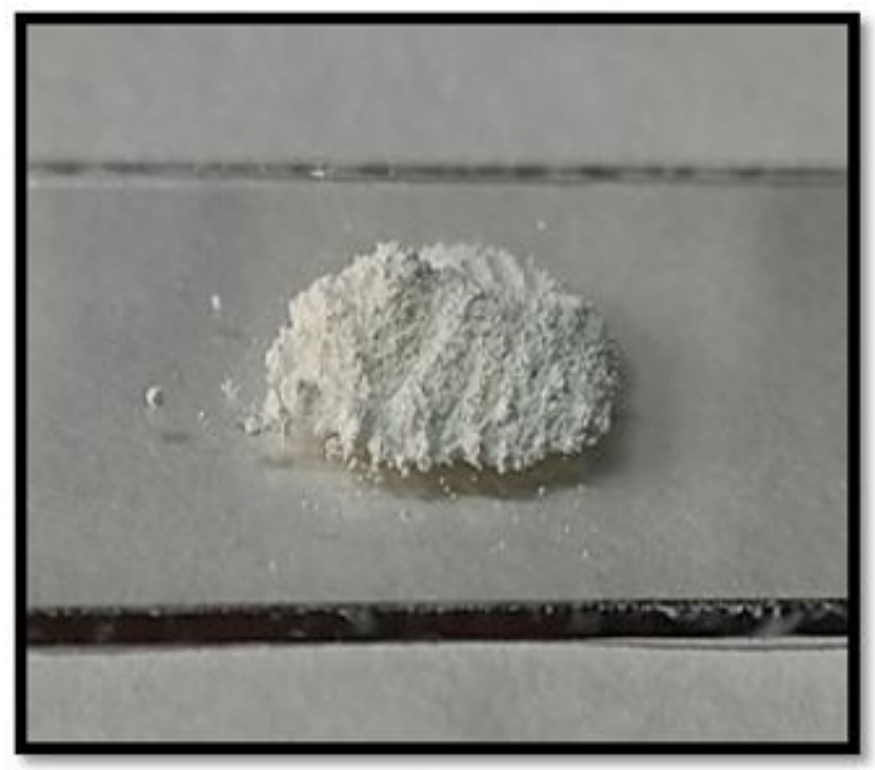

(B)

\section{Figure 1}

Photo of TiO2 prepared using a gas-mixing ratio of 50:50 and inter-electrode distance $4 \mathrm{~cm}$ at deposition time $3: 30 \mathrm{~h}$ as $(\mathrm{A})$ thin film and $(\mathrm{B})$ powder 


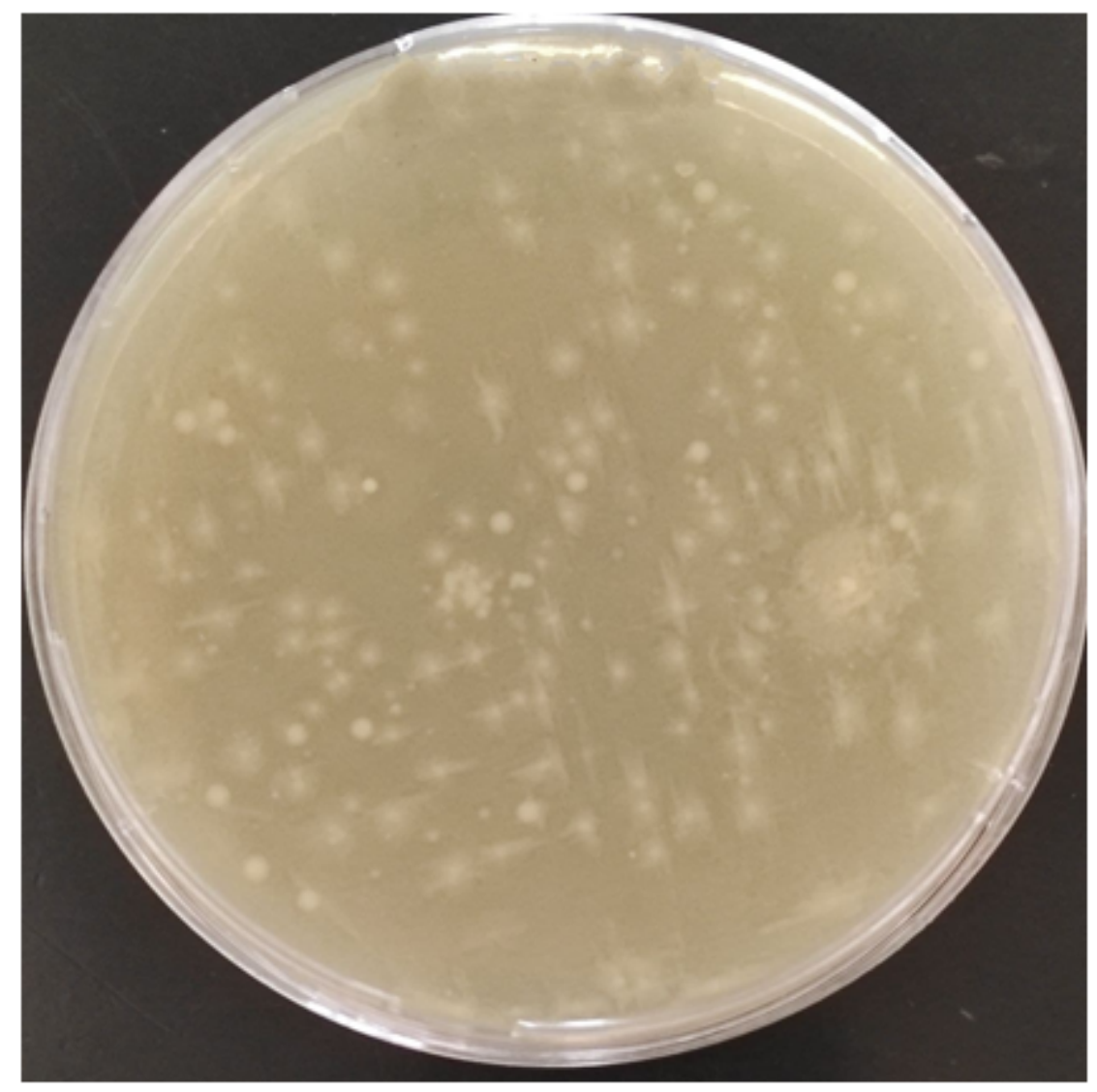

Figure 2

Photo of bacteria (E. coli) before treatment 

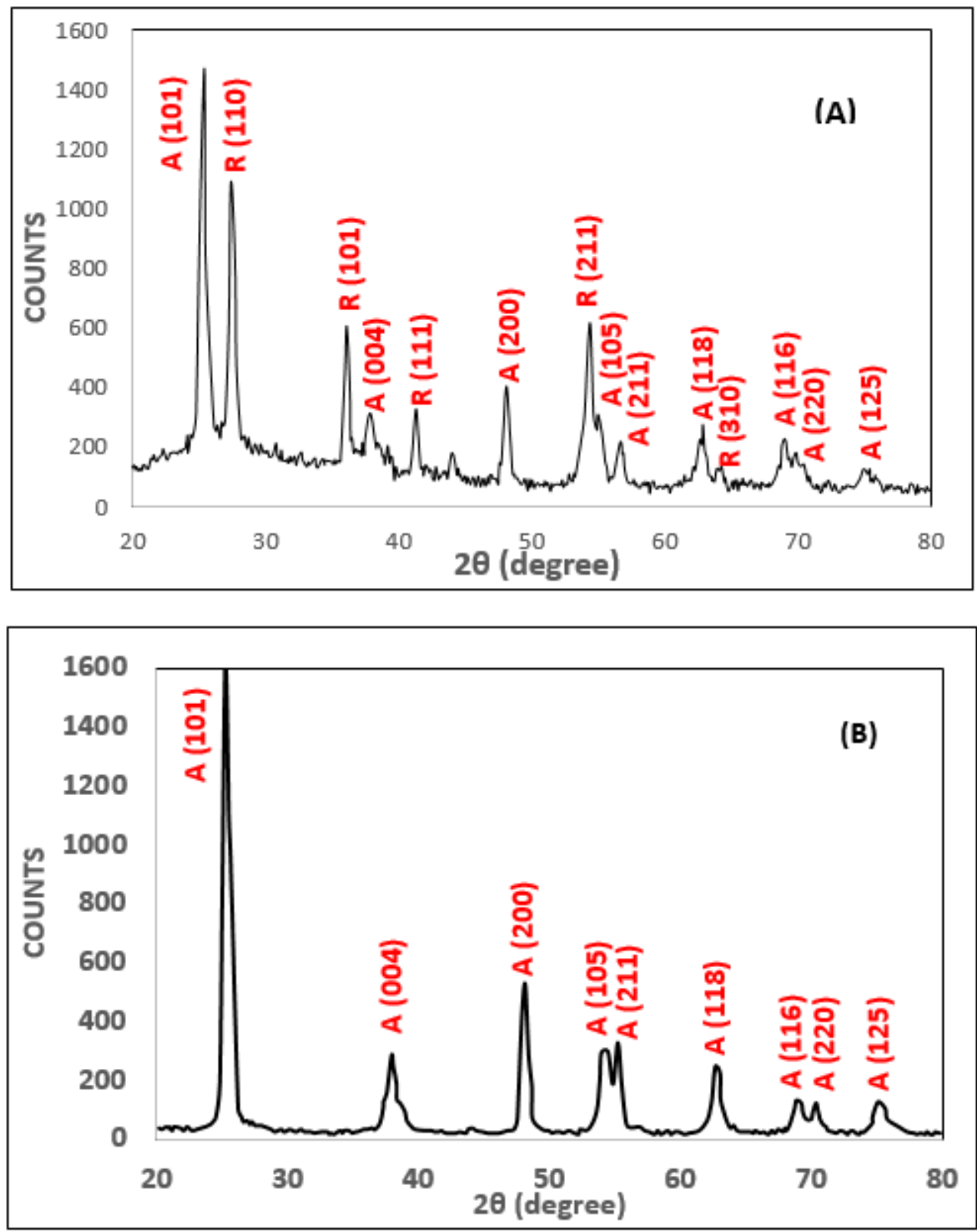

Figure 3

XRD patterns of TiO2 nanostructures prepared using a gas mixing ratio of 50:50 and inter-electrode distance $4 \mathrm{~cm}(\mathrm{~A})$ mixed-phase at deposition time $4 \mathrm{~h}$ and (B) single-phase at deposition time $3 \mathrm{~h}$ with heat sink 


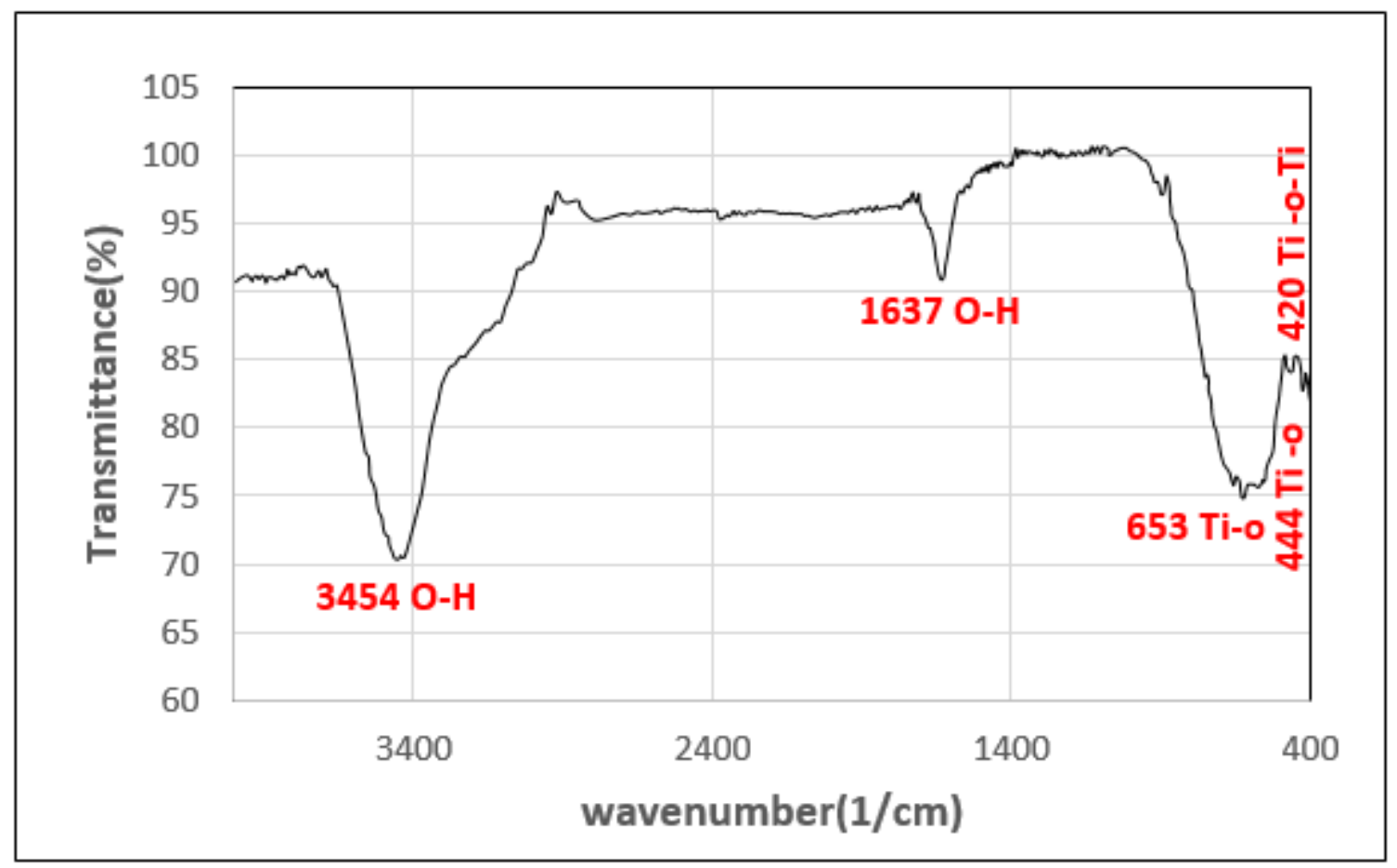

\section{Figure 4}

The FTIR spectrum of TiO2 sample of mixed-phase prepared using Ar: 02 mixing ratio of 50:50 and deposition time of 4 hour
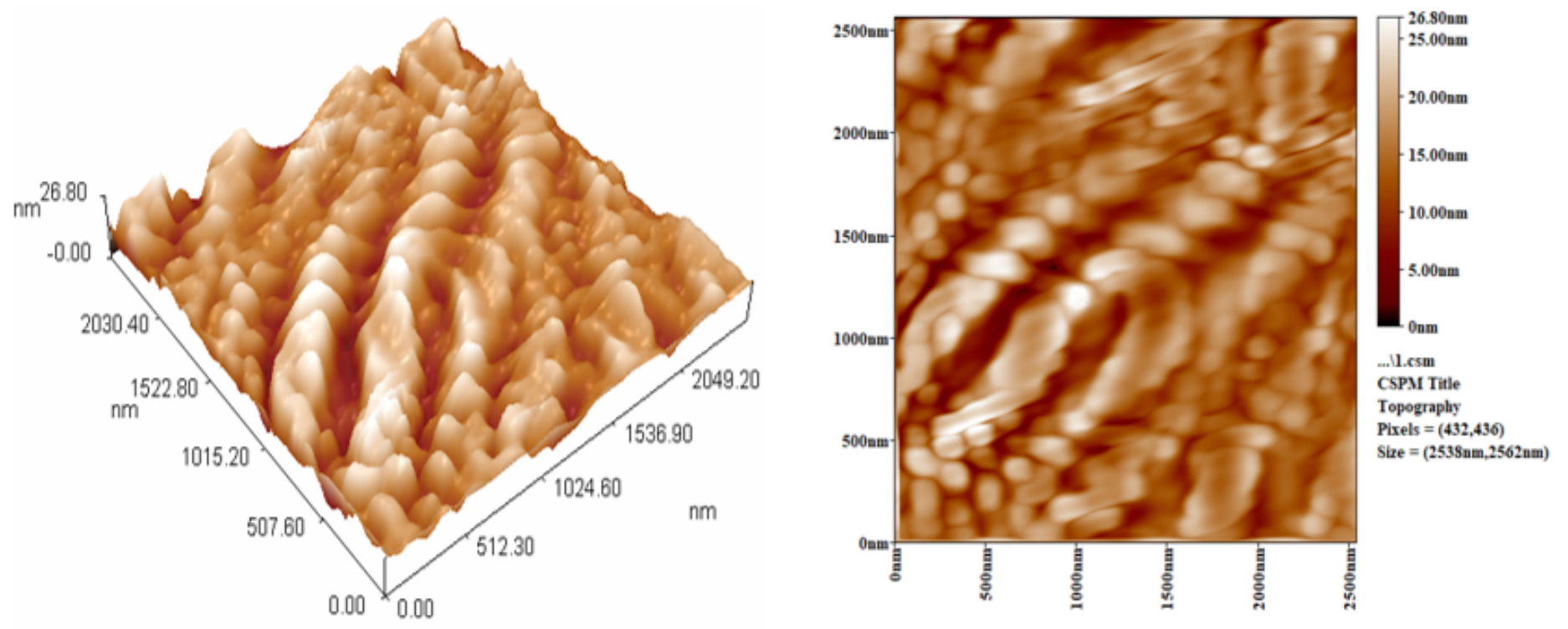

Figure 5

AFM images of TiO2 nanoparticles in two and three dimensions 


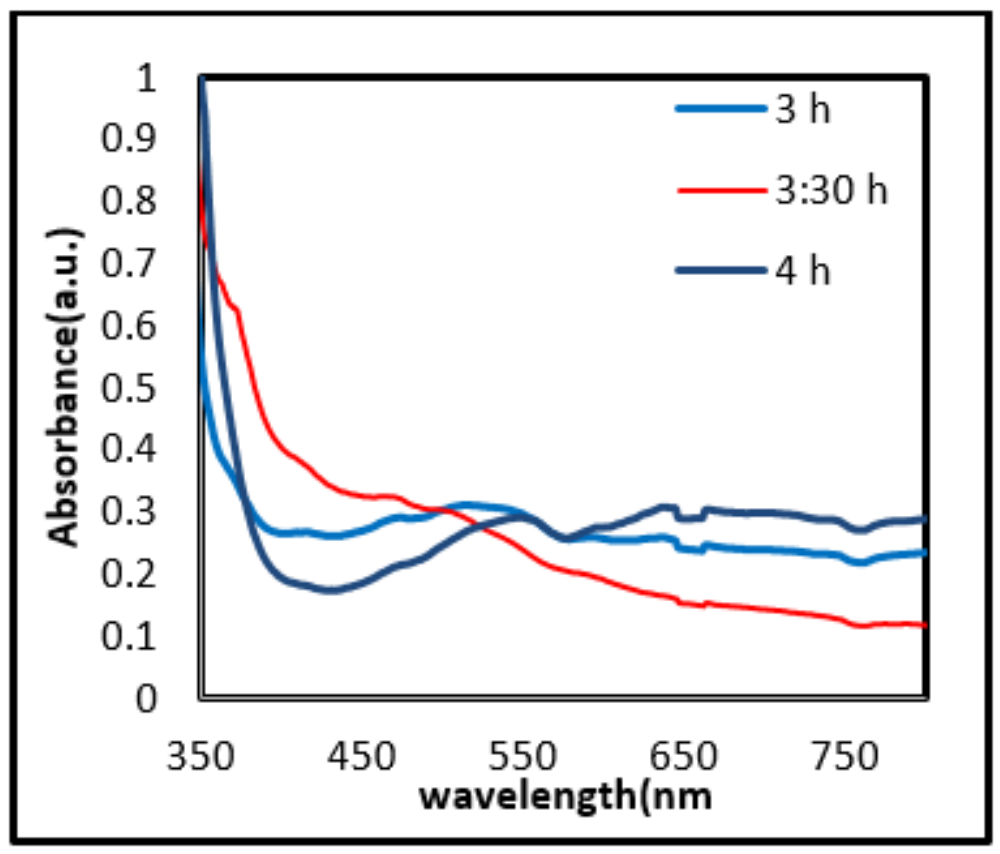

Figure 6

Absorption spectra of the mixed-phase TiO2 prepared using Gas mixing ratio of 50:50 at deposition time 3h (rutile content 40 wt.\%), 3:30h (rutile content 46 wt.\%), and 4h (rutile content 50wt.\%)

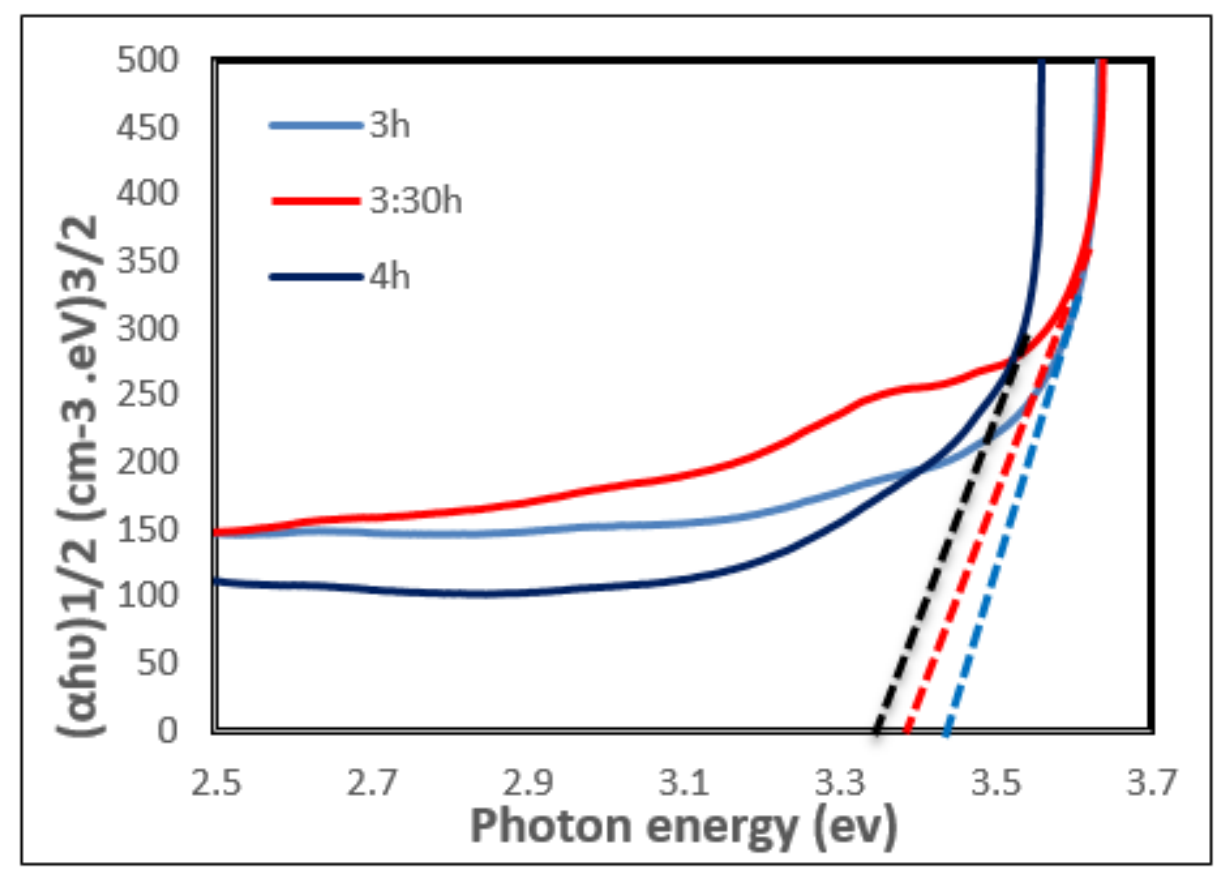

Figure 7

Determination of Energy band gap of mixed-phase TiO2 prepared using gas mixing ratio of 50:50 at deposition time $3 \mathrm{~h}$ (rutile content $40 \mathrm{wt} . \%$ ), 3:30h (rutile content $46 \mathrm{wt} . \%$ ), and $4 \mathrm{~h}$ (rutile content $50 \mathrm{wt} . \%$ ) 


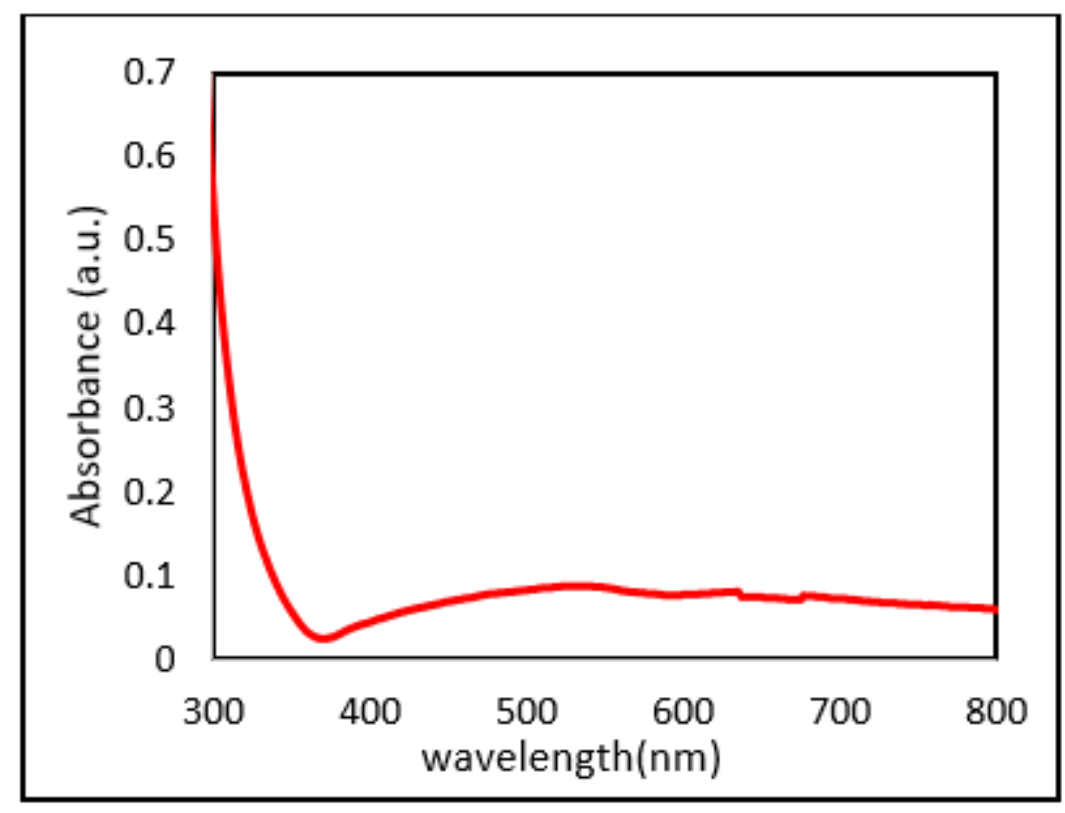

Figure 8

Absorption spectrum of single-phase TiO2 prepared using the gas-mixing ratio of 50:50 at deposition time $3 h$

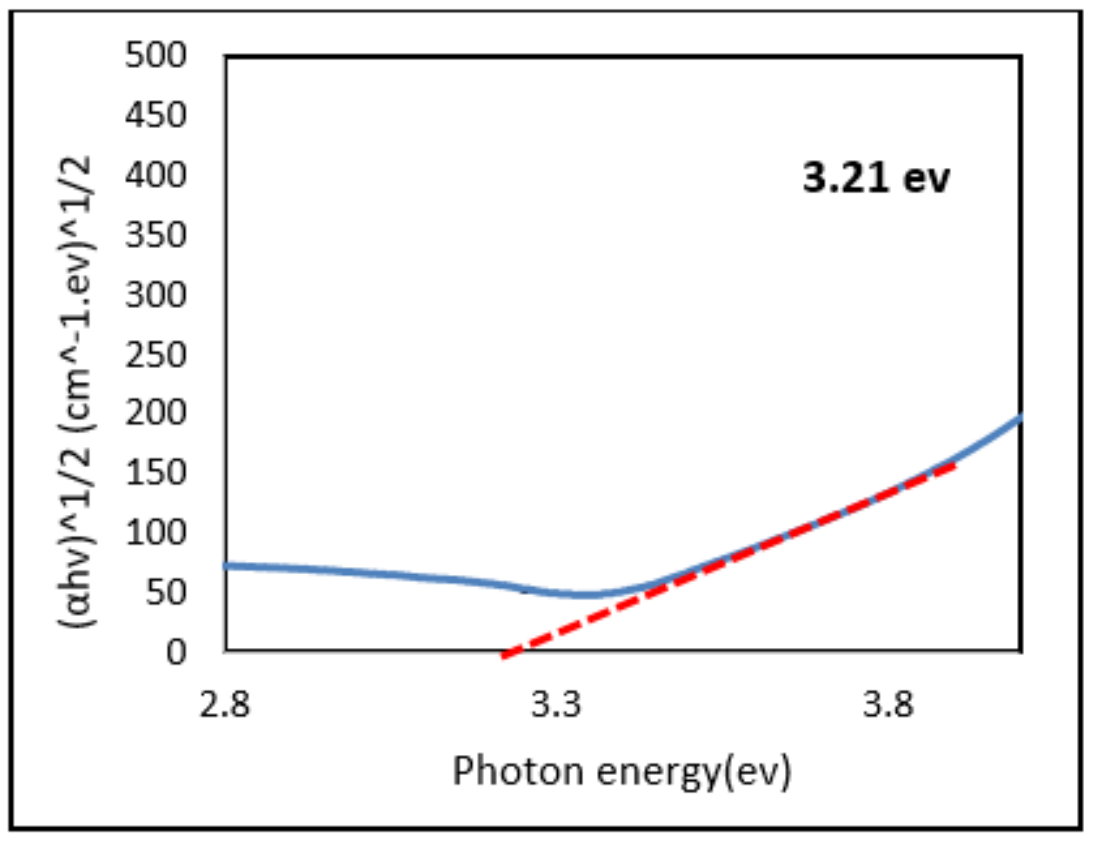

Figure 9

Determination of Energy band gap of single-phase TiO2 prepared using gas mixing ratio of 50:50 at deposition time $3 \mathrm{~h}$ 

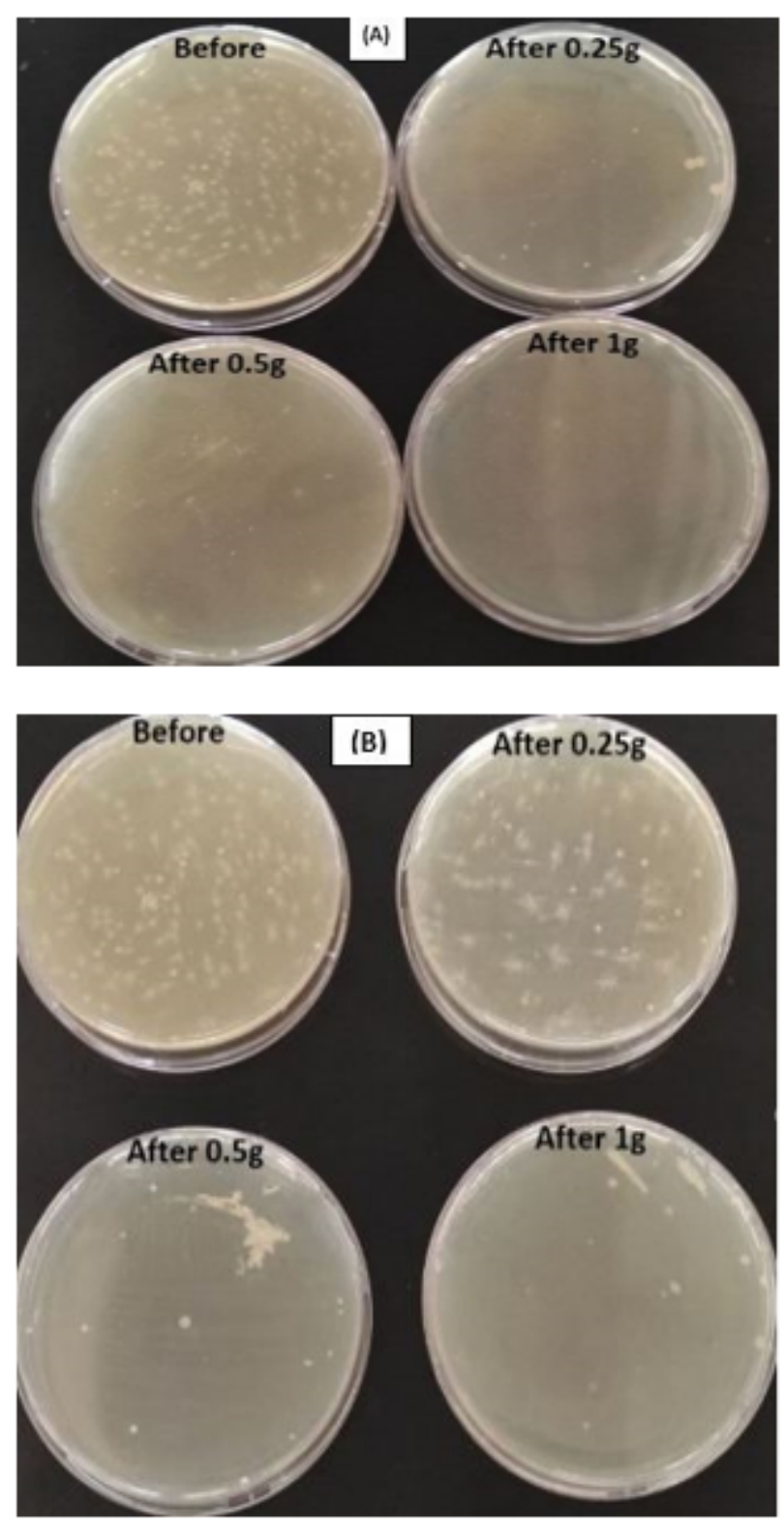

Figure 10

Photos show the influence of $\mathrm{TiO} 2$ nanoparticles (A) single phase (anatase) (B) mixing phase (rutile/anatase) as anti-bacteria at different concentration and with 1:30 hours uv. Irradiation 